BULLETIN Bulletin hispanique

HISPANIQUE Université Michel de Montaigne Bordeaux

119-1 | 2017

Autorité et pouvoir dans le théâtre du Siècle d'Or

\title{
Revisión de una obra atribuida a Lope de Vega
}

La famosa comedia otomana, un posible caso de refundición

Daniel Fernández Rodríguez

\section{(2) OpenEdition}

Journals

Edición electrónica

URL: http://journals.openedition.org/bulletinhispanique/4979

DOI: 10.4000/bulletinhispanique.4979

ISBN: 979-10-300-0142-6

ISSN: 1775-3821

Editor

Presses universitaires de Bordeaux

Edición impresa

Fecha de publicación: 15 junio 2017

Paginación: 353-370

ISBN: 979-10-300-0141-9

ISSN: 0007-4640

Referencia electrónica

Daniel Fernández Rodríguez, « Revisión de una obra atribuida a Lope de Vega », Bulletin hispanique [En línea], 119-1 | 2017, Publicado el 15 junio 2020, consultado el 11 septiembre 2020. URL : http:// journals.openedition.org/bulletinhispanique/4979; DOI : https://doi.org/10.4000/bulletinhispanique. 4979 


\title{
Revisión de una obra atribuida a Lope de Vega: La famosa comedia otomana, un posible caso de refundición ${ }^{1}$
}

\author{
Daniel Fernández Rodríguez \\ Universitat Autònoma de Barcelona
}

La famosa comedia otomana a été attribuée récemment à Lope de Vega. Cependant, une analyse détaillée de l'orthologie, de la versification et de la rime montre que l'on ne dispose pas de données suffisantes pour certifier que l'auteur soit Lope. En revanche, il est plausible que le texte conservé soit le produit d'une refonte.

Mots-clés: La famosa comedia otomana, Lope de Vega, El Otomano famoso, refonte.

La famosa comedia otomana ha sido atribuida en fechas recientes a Lope de Vega. Sin embargo, un análisis minucioso de su ortología, versificación y rimas demuestra que no contamos con datos suficientes como para certificar la autoría lopesca. Resulta más probable, en cambio, que el texto conservado sea el resultado de una refundición.

Palabras clave: La famosa comedia otomana, Lope de Vega, El Otomano famoso, refundición.

"La famosa Comedia Otomana" has, in recent years, been attributed to Lope de Vega. However, a careful study of its orthoepy, versification and rhyme shows that this play can't be credited to Lope. Instead, it is more likely that the conserved text is the result of a rewriting.

Keywords: La famosa comedia otomana, Lope de Vega, El Otomano famoso, rewrite.

1. He podido llevar a cabo este artículo gracias a una beca FPU del Ministerio de Educación y a mi participación en el proyecto de investigación «Edición y estudio de treinta y seis comedias de Lope de Vega» (FFI2012-35950), financiado por el Ministerio de Economía y Competitividad (España). Agradezco a Gonzalo Pontón, Guillermo Serés y Ramón Valdés sus amables y sabios consejos. 
G $\mathrm{n}$ un artículo aparecido en 1994, María Dolores Cigüeńa Beccaria C anunciaba el hallazgo de una pieza de teatro anónima, titulada La famosa comedia otomana ${ }^{2}$, y exponía las razones por las cuales cabía identificar dicha obra con El Otomano famoso -título que aparece en la primera lista de El peregrino en su patria (1604)-, razones que ampliaría en un artículo de 1995. $\mathrm{Al}$ año siguiente la misma autora publicó una edición de la comedia, atribuida ya a Lope de Vega y con el título El Otomano famoso. En este artículo pretendo revisar los datos ofrecidos por Beccaria con el fin de reconsiderar la atribución de la pieza a Lope. Para ello, me valdré de métodos objetivos como el estudio de la versificación estrófica, la ortología y la rima.

\section{UN CASO EVIDENTE DE DETURPACIÓN TEXTUAL}

El texto de La famosa comedia otomana-de aquí en adelante, La Otomanase encuentra muy deturpado. En su edición, Beccaria advierte la presencia de 7 versos mutilados, 3 quintillas con versos de más, varios casos de hipometría e hipermetría, 40 estrofas a las que les faltan uno o más versos ${ }^{3}$, así como una veintena de errores manifiestos que afectan al sentido del pasaje y otros tantos que rompen la rima. La editora lleva a cabo además una "corrección de errores evidentes del texto sin indicarlo» (Beccaria 1996: 53). En efecto, un análisis detenido de La Otomana revela la presencia de más de ochenta errores en el manuscrito, enmendados pero no señalados por Beccaria en las notas de su edición, los cuales delatan una transmisión textual muy accidentada, en la que parece segura la intromisión de algún autor de comedias -o incluso la de algún actor-, y en la que no cabe descartar asimismo la intervención de algún memorilla, ya que La Otomana fue «probablemente tomada al oído por alguno de los espectadores acostumbrados a vender a otros cómicos los textos de obras cuya representación presenciaba» (Lapesa 1996: 7-8). El escaso número de versos del último acto (699) y alguna que otra laguna argumental ${ }^{4}$ constituyen indicios de que probablemente se hayan perdido varios fragmentos del texto. En vista de todo ello no parecen muy exageradas las palabras de Lope: «No hay cortesana que haya corrido a Italia, las Indias y la casa de Meca que vuelva tan desfigurada como una pobre comedia, que ha corrido por aldeas, criados y hombres que viven de hurtarlas y de añadirlas ${ }^{5}$."

2. La famosa comedia otomana se encuentra en el códice II-797 de la Biblioteca de Palacio de Madrid. Para una descripción detallada del mismo, remito a Beccaria (1995: 85-87).

3. En la quintilla que comienza en el verso 1861 Beccaria omite un verso que es perfectamente legible en el manuscrito: «dos vezes me das la vida» (f. 46v). En las citas del manuscrito no modernizo la ortografía.

4. Véase Iriso (1997: 221).

5. Tomo la cita de Dixon (1996: 57-58). 


\section{Presencia de Lucinda e hipotética fecha de La Otomana}

La presencia en La Otomana de un personaje llamado Lucinda -seudónimo literario de Micaela de Luján en las obras de Lope-, así como el tratamiento que recibe en la obra, es uno de los argumentos esgrimidos por su editora para atribuirla al Fénix y fecharla en 1598-1599, «momento en que Lope, tras haber conocido a Micaela, inicia el proceso de seducción sin haber conseguido todavía sus favores» (Beccaria 1996: 46). Beccaria cita oportunamente varios textos lopescos en los que aparece el personaje de Lucinda y que presentan rasgos estilísticos semejantes a los de La Otomana, entre los cuales destaca el uso de rimas idénticas formadas por las palabras Lucinda, linda y rinda. Este, pues, es un primer factor que apoyaría la posible atribución de la comedia a Lope, además de sugerir una fecha temprana, situada en torno a 1598-1599. Beccaria parte de la premisa de que La Otomana se corresponde con El Otomano famoso, título que aparece citado en El peregrino en su patria - publicado a principios de 1604, pero cuya fecha de aprobación data del 25 de noviembre de 1603-, por lo que en cualquier caso no podría ser muy posterior. Además, según Beccaria, la versificación estrófica de la pieza confirma la fecha ofrecida por el tratamiento del personaje de Lucinda. Veámoslo detenidamente.

\section{VERSIFICACIÓN ESTRÓFICA}

Habida cuenta del deterioro textual de La Otomana, el estudio de la versificación será el método más fiable para la determinación de su autoría ${ }^{6}$. Ofrezco a continuación un breve resumen del uso de las distintas formas métricas:

\begin{tabular}{|l|c|c|c|}
\hline \multicolumn{1}{|c|}{ Estrofas } & Total & Porcentajes & Pasajes \\
\hline 429 quintillas & 2145 & 83,6 & 11 \\
\hline 81 redondillas & 324 & 12,5 & 4 \\
\hline romance & 54 & 2,1 & 1 \\
\hline sueltos (endecasilabos) & 43 & 1,7 & 2 \\
\hline mote $(a b b)$ & 3 & 0,1 & 1 \\
\hline
\end{tabular}

El rasgo más característico de La Otomana es su alto porcentaje de quintillas $(83,6 \%)$. Amparándose en los datos ofrecidos por Morley y Bruerton, Beccaria (1996: 49) recuerda que en el periodo de 1598-1599 Lope compuso varias obras en las que abunda esta estrofa. Su comedia con un porcentaje mayor de quintillas es El ganso de oro (62,7 \%), que, según Morley y Bruerton, fue escrita entre 1588 y 1595 . A esta le sigue, con un 57,2 \%, La pastoral de Jacinto,

6. "The need for an absolutely authentic text is not so great here as in the field of scansion.» (Morley 1937: 284) 
compuesta en esas mismas fechas a juicio de Ambrosi (1997: 19-24). Además de estas dos, antes de 1603 Lope escribió cerca de quince comedias cuyo metro predominante es la quintilla, con unos porcentajes que oscilan entre el $35 \%$ y el $55 \%{ }^{7}$. Como vemos, La Otomana presenta un porcentaje $(83,6 \%)$ muy superior. En concreto, rebasa ampliamente los de las obras con mayor número de quintillas escritas entre 1598 y 1599, supuesta fecha de composición de $\mathrm{La}$ Otomana a juzgar por la presencia de Lucinda. Algunos ejemplos: El Alcaide de Madrid, escrita antes de junio de 1599, contiene un 48,6 \%; La hermosa Alfreda (compuesta probablemente entre 1598 y 1600), un 53,6 \%, y Las pobrezas de Reinaldos y el Blasón de los Chaves, ambas de 1599, un 39,7 \% y un $52 \%$, respectivamente.

En cambio, otros autores y obras de finales del siglo XVI y principios del XVII sí presentan unos usos métricos semejantes a los de La Otomana, especialmente entre el grupo de los dramaturgos valencianos. Es el caso de algunas comedias de Francisco Agustín Tárrega, como La sangre leal (97,8 \% de quintillas), La fundación de la Orden de Nuestra Señora de la Merced (90,5\%), La enemiga favorable (97,9\%), El cerco de Rodas (93,8 \%) o El esposo fingido (70,7 \%). En cuanto a Gaspar Aguilar, Los amigos enojados (90,7\%), La venganza honrosa (97,5 \%) y Los amantes de Cartago (86,1\%) ofrecen asimismo porcentajes semejantes a La Otomana. También la obra de Miguel Beneyto (El hijo obediente, 85,1\%) y Carlos Boyl (El marido asegurado, 88,5\%) arroja datos parecidos ${ }^{8}$. Todas estas comedias fueron escritas en torno a 1600. Los amantes de Cartago, de Aguilar, presenta el terminus ad quem más tardío (1608), pero su redacción tuvo lugar probablemente unos ańos antes, pues «parece improbable que un 86\% de quintillas sea muy posterior a 1600» (Bruerton 1956: 353). En cuanto a las demás obras analizadas por Bruerton, La sangre leal de Tárrega y El hijo obediente de Beneyto fueron compuestas antes de 1600, mientras que la fecha de composición de La fundación de la Orden de Nuestra Señora de la Merced, La enemiga favorable, El cerco de Rodas y El esposo fingido de Tárrega no debe situarse más allá de 1602. Por último, el terminus ad quem de Los amigos enojados de Aguilar y de El marido asegurado de Boyl se corresponde con los años 1603 y 1604 respectivamente.

Pero no solo entre el grupo de los valencianos hallamos porcentajes tan elevados de quintillas. En el volumen Doce comedias de varios autores, impreso en Tortosa en 1638, figura la Famosa comedia del cerco de Túnez y ganada de la Goleta por el emperador Carlos quinto, atribuida a "Juan Sánchez, natural de Piedrahíta", que cuenta con un 79,9\% de quintillas (Arata 1989: 87-89). En el estudio de la versificación de Mira de Amescua llevado a cabo por Williamsen (1977: 165), se evidencia una preferencia por la quintilla en la producción temprana del autor, que en el caso de La confusión de Hungría se eleva hasta el 89,7 \%. Bruerton (1944: 224) señaló asimismo que El valeroso español, de

7. Morley y Bruerton (1968: 111-112).

8. Estos datos proceden de Bruerton (1956), salvo el de La venganza honrosa, tomado de un artículo suyo anterior (1944: 224). 
Gaspar de Ávila, cuenta con un 73,3\% de quintillas. Por su parte, Ojeda Calvo (1996: 26) constata que la anónima El hijo de la cuna de Sevilla, fechable al parecer de la estudiosa en torno a 1600 , presenta un $88,9 \%$ de quintillas.

Según señala Bruerton (1956: 362), «los valencianos diferían de sus contemporáneos madrileños en su empleo de las quintillas, del romance y de los endecasílabos». La Otomana no solo se asemeja a los usos métricos del grupo de los valencianos debido al gran empleo de las quintillas, sino también por la escasa presencia del romance y de versos italianos. Mientras que en Lope hay varias obras con un bajo porcentaje de romances, son muy pocas las comedias con un porcentaje tan escaso de versos italianos. Algunas de ellas pertenecen a una etapa muy temprana de su producción. Se trata de El hijo venturoso, con un $0 \%$ de versos italianos, El príncipe melancólico, con un $0,4 \%$ (ambas escritas entre 1588 y 1595), y La ingratitud vengada, de 1585-1595'10, que cuenta con un 1,8\% de versos italianos. De fecha próxima a la hipotética datación de La Otomana es La prisión sin culpa (1599-1600), con un 2,7 \% ${ }^{11}$. Algo posteriores, escritas en 1603, El Arenal de Sevilla y La gallarda toledana cuentan respectivamente con un $1,5 \%$ y un $1,4 \%{ }^{12}$.

En cuanto al tipo de quintillas empleadas, en La Otomana se encuentran las cinco combinaciones recogidas por Díaz Rengifo en su Arte poética de 1592 (Morley y Bruerton 1968: 38) ${ }^{13}$ :

$\begin{array}{lll}1-\mathrm{ABABA} & 286 & (66,6 \%) \\ 2-\mathrm{ABBAB} & 19 & (4,4 \%) \\ 3-\mathrm{ABAAB} & 26 & (6 \%) \\ \text { 4- AABAB } & 4 & (0,9 \%) \\ 5-\mathrm{AABBA} & 61 & (14,2 \%)\end{array}$

La combinación mayoritaria es la 1 (ABABA), seguida de lejos por la 5 (AABBA), mientras que los tipos 2, 3 y 4 apenas alcanzan en total el $11 \%{ }^{14}$. Beccaria, en cambio, afirma que «de los diferentes tipos de quintillas que existen, dos son los más utilizados por Lope: los que Morley y Bruerton

9. Los datos que se ofrecen en este párrafo proceden de Morley y Bruerton (1968).

10. Morley y Bruerton (1968: 247) ofrecen como fecha «1590-1595, posiblemente 15851595?». Sobre la discutida fecha de composición de La ingratitud vengada, véase ahora Boadas (2015: 913-916).

11. Sigo la datación propuesta por Rafael Ramos (2009: 873).

12. Para estas fechas, véanse Cornejo (2012: 461-466) y Fernández Rodríguez (2014: 280283) respectivamente.

13. Debido a diversas lagunas textuales, achacables probablemente a los avatares de la transmisión, resulta imposible distinguir el tipo de combinación empleada en 33 quintillas (el $7,9 \%$ del total).

14. Las quintillas del tipo 2 son las que comienzan en los vv. 106, 141, 146, 348, 788, 828, $1073,1078,1118,1163,1238,1248,1801,2021,2151,2186,2206,2276$ у 2456 . Al tipo 3 pertenecen las quintillas de los vv. 76, 638, 743, 748, 763, 813, 823, 838, 878, 893, 1098, $1153,1198,1233,1692,1717,1727,1866,2136,2246,2296,2461$ y 2565 . Finalmente, las del tipo 4 se encuentran en los vv. 131, 2181, 2326 y 2520 (para esta última, véase la enmienda que propongo en el apartado «Rima»). 
denominan tipo $1(a b a b a)$ y tipo $5(a b b a b)^{15}$. La Otomana utiliza en todo caso ambos tipos y no otros» (Beccaria 1995: 94).

El uso de los distintos tipos de quintillas se asemeja bastante a la práctica de Lope, que, según Morley y Bruerton (1968: 38), prefiere la no 1 en primer lugar y la $\mathrm{n}^{\circ} 5$ en segundo, a gran distancia de la no 2 y la $\mathrm{n}^{\circ} 3$. Con todo, hay un detalle que contradice los usos lopescos. Me refiero a la presencia de cuatro quintillas del tipo 4, casi tantas como las que aparecen en toda su producción: «No hemos hallado más que seis estrofas del tipo 4 en otras tantas comedias.» (Morley y Bruerton 1968: 108)

Otro elemento ajeno a la versificación lopesca es la presencia de un «mote» (en el sentido de «enigma, texto breve ingenioso»), ideado por la infanta para retrasar su boda. Tal y como edita el texto Beccaria, tras una relación en romance por parte de Lucinda (vv. 231-284), tendríamos una quintilla, un «mote», y a continuación una serie de veinte quintillas:

$$
\begin{aligned}
& \text { Otомán Tanto a tu bien me acomodo } \\
& \text { que holgara, con el garrote, } \\
& \text { darles la muerte del todo. } \\
& \text { LuCINDA Di, ¿quieres saber el mote? }{ }^{16} \\
& \text { OTOMÁn ¿Cómo dice? } \\
& \text { LuCINDA Deste modo: } \\
& \text { «Yo he parido sin ser madre }
\end{aligned}
$$

(vv. 285-292)

Así pues, el mote estaría formado por un terceto octosilábico con rima $a b b$ (vv. 290-292), metro especialmente cultivado en la poesía del siglo XV. Le Gentil (1981: 21-22) aporta numerosos ejemplos de motes en forma de tercetos, entre los que destacan los incluidos en el Cancionero general, reunido por Hernando del Castillo en 1511. Pues bien, según los datos recogidos por Morley y Bruerton (1968: 181-188), no se registra en la obra del Fénix ni un solo terceto de este tipo.

Así las cosas, cabría plantear la posibilidad de que el terceto sea consecuencia de la deturpación textual del pasaje, y que en realidad no apareciera en el texto original. Un poco más adelante, topamos con los versos siguientes:

\begin{tabular}{ll} 
Orodante & $\begin{array}{l}\text { Para podello mirar } \\
\text { tu Majestad otra vez, } \\
\text { mande el mote relatar } \\
\text { cómo dice. }\end{array}$ \\
INFANTA & \multicolumn{1}{c}{ Deste modo: } \\
& $\begin{array}{l}\text { Yo he parido sin ser madre } \\
\text { un monstruo cobarde y fuerte } \\
\text { compuesto de vida y muerte». } \\
\text { ReY }\end{array}$
\end{tabular}

15. Parece que Beccaria confunde el tipo 5 (AABBA) con el 2 (ABBAB).

16. En el manuscrito se lee «queres» (f. 8v). Beccaria edita «queréis», pero Lucinda en todo momento trata a Otomán de tú, por lo que transcribo «quieres». 


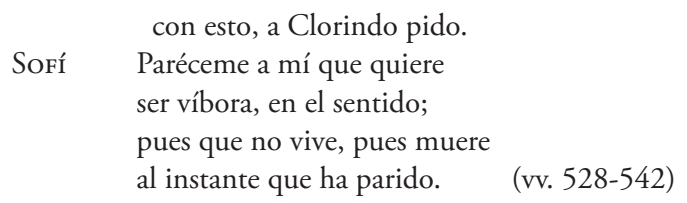

En su edición, Beccaria no parece advertir que el primer verso de la segunda quintilla no rima como debiera (modo no rima con fuerte ni muerte). Es necesario, a mi juicio, enmendar modo por suerte, corrección que no altera el sentido pero que sí restaura la rima. Pues bien, volviendo al pasaje del que nos ocupábamos anteriormente, observamos que el verso 289 es idéntico al 533, de tal manera que es posible realizar la misma enmienda ("Otomán ¿Cómo dice? / Lucinda Desta suerte») ${ }^{17}$. Desaparece así el terceto, pero las estrofas resultantes tampoco son del todo satisfactorias, ya que obtendríamos lo que parecen ser dos cuartetas, o dos quintillas con un verso menos cada una. La extrema deturpación textual del manuscrito (el cual contiene múltiples estrofas mutiladas) impide emitir juicios seguros al respecto.

En resumidas cuentas, la versificación de La Otomana no se corresponde con los usos lopescos. En cambio, otros autores del Siglo de Oro -especialmente los dramaturgos valencianos- sí presentan características semejantes, sobre todo por lo que respecta al uso de la quintilla como metro ampliamente mayoritario, empleado en más del $80 \%$ de los versos, un porcentaje inusitado en Lope.

\section{OrtologÍA}

Según Beccaria (1995: 95), «La Otomana en principio no contradice los usos ortológicos habituales de Lope, salvo en los casos presumiblemente ajenos a la propia obra, como son las correcciones emanadas de los hábitos de pronunciación propios del copista». No obstante, en mi opinión un análisis minucioso demuestra que el texto se opone constantemente a los usos lopescos. Uno de los ejemplos más claros es la presencia, hasta en tres ocasiones, del bisílabo veamos (siempre trisílabo en Lope $)^{18}$ :

$$
\begin{aligned}
& \text { veamos lo que sabe hacer (v. 497) } \\
& \text { Veamos qué dirá el pastor (v. 597) } \\
& \text { Pirro, ¿qué dices? -Que veamos (v. 2419) }
\end{aligned}
$$

A lo largo de la comedia aparecen varias palabras que no se avienen con la ortología lopesca ${ }^{19}$. Es el caso de los monosílabos creo («Yo creo que vendrá temprano», v. 2399) y huir («de lo que el hombre huir debe», v. 1928), voces

17. Esta enmienda viene respaldada por la presencia de dos quintillas que contienen exactamente las mismas rimas en -uerte (vv. 328-332 y 1951-1955).

18. Véase Poesse (1949).

19. Salvo que se indique lo contrario, todos los versos citados son octosílabos. 
que en Lope contienen siempre dos sílabas ${ }^{20}$. En el endecasílabo «Criélo en el monte como mejor pude» (v. 2500), la voz criélo es bisílaba, mientras que las formas crié y crió siempre llevan diéresis en Lope (Poesse 1949: 41-44). La Otomana presenta además varios casos de hiato en el grupo -ie- no registrados por Morley (1927: 528) ni Poesse (1949: 41-44). Se trata de versos que han sido corregidos por Beccaria en su edición:

•v. 72- muy bien lo podría ser («muy bien lo podra ser», f. 3v)

•v. 77- el sol ya quiere salir («el sol quiere salir», f. 3v)

-v. 142- ¡Otomano, ten sosiego! («otoman ten sociego», f. 5r)

- v. 206- ¡Qué fieros los golpes carga! («que fieros golpes carga», f. 7r)

-v. 539- Paréceme a mí que quiere («Pareceme que quiere», f. 15r)

•v. 1270- Quiero por solo un regalo («quiero por un regalo», f. 32v)

•v. 1896- y que no tiene cabello («q no tiene cabello», f. 47v)

En estos ejemplos, las palabras bien, quiere, sosiego, fieros, quiere, quiero y tiene podrían llevar diéresis. Especialmente llamativo es el caso de quiere y quiero, que hasta en tres ocasiones se encuentran en dichas circunstancias, y que tampoco están registrados ni en Morley (1927: 528) ni en Poesse (1949: 41-44). También es ajena al Fénix la posible diéresis en suegro en el verso 1325 ("y al tu suegro venci», f. 34r), que en la edición de Beccaria figura como "y al suegro tuyo vencí», eliminando así toda posibilidad de diéresis. Las enmiendas de Beccaria son verosímiles, pero, en mi opinión, más que subsanar errores evidentes, a menudo corrigen posibles hábitos ortológicos ajenos al supuesto autor del texto, o sea, a Lope de Vega.

En otras ocasiones, La Otomana presenta usos ortológicos francamente excepcionales en Lope. Un ejemplo es la expresión ea, casi siempre bisílaba para el Fénix ${ }^{21}$, que es dos veces monosílaba en La Otomana: «iEa, pastores! ¡Yo he ganado» (v. 114) y «Ea, de presto aguijen todos» (v. 1809). Por otro lado, en la obra aparece un fiel con diptongo al final de verso («más lindo que tú eres fiel», v. 1990), mientras que Poesse (1949: 40 y 43) registra 11 casos con diéresis frente a uno solo con diptongo. Encontramos asimismo un ruido bisílabo (“¿Qué ruido es ése, pastor?», v. 1806), extrañísimo en Lope: entre los 44 casos recogidos por Morley (1927: 529) y Poesse (1949: 46), 41 son trisílabos, dos son dudosos y solamente uno es bisílabo ${ }^{22}$. La comedia contiene por otra parte un sería condicional cuya acentuación recae en la $a$, es decir, que forma sinéresis («sería rey de Negroponte», v. 264), fenómeno documentado solamente en uno de los nueve ejemplos recogidos por Morley (1927: 533) y Poesse (1949: 33-38).

20. Consúltese el índice de Poesse (1949).

21. Poesse (1949: 22-25) recoge 55 casos de ea bisílabo frente a 2 monosílabos, mientras que Morley (1927: 530) aporta un caso monosílabo.

22. Según se transcribe en la edición de Beccaria, el verso 1713 («señor, contra tu honor cruel») contiene un cruel monosílabo, muy extraño en Lope (Poesse registra un único caso). Sin embargo, el verso que figura en el manuscrito es «ser contra tu onor cruel» (f. 43r), que o bien contiene un cruel bisílabo y sinalefa entre tu y honor, o bien cruel es monosílabo y hay hiato entre tu y honor. Esta última posibilidad contradice los hábitos de Lope. 
En lo que concierne al estudio de los grupos de palabras, y en contra de lo afirmado por Beccaria, La Otomana presenta asimismo abundantes usos contrarios a $\operatorname{Lope}^{23}$, como por ejemplo cuatro hiatos ante vocal átona en palabras que empiezan con $h$ aspirada. Poesse (1949: 63-64) registra solamente tres casos de hiato, frente a 2176 ejemplos de sinalefa.

$$
\begin{aligned}
& \text { ¿Qué haré, triste de mí? (v. 191) } \\
& \text { aquella hermosa cara (v. 1372) } \\
& \text { me hacéis piedra dorada (v. 2064) } \\
& \text { ¿Qué sé hacer? Sé tomar (v. 2329) }
\end{aligned}
$$

La comedia presenta además 15 casos de hiato entre dos vocales átonas de diferentes palabras, mientras que Morley (1927: 539) y Poesse (1949: 67-68) solo recogen tres en los 34 autógrafos estudiados ${ }^{24}$ :

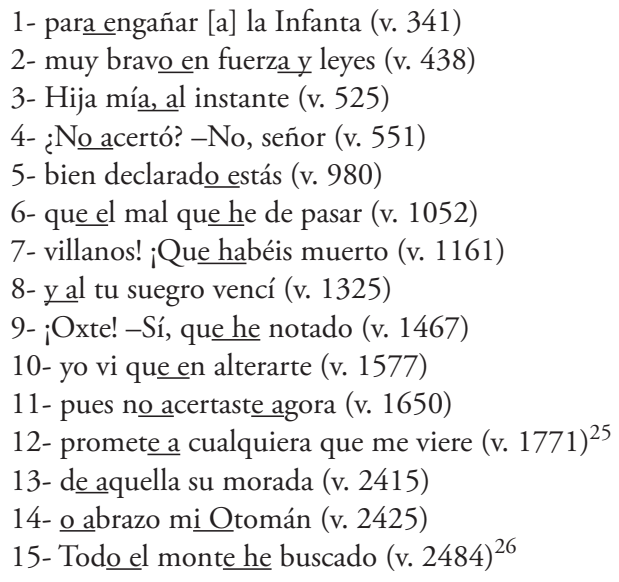

Otros versos, en cambio, presentan un hiato ilusorio, puesto que una sencilla enmienda permite paliar la falta de sentido o la incongruencia gramatical. En otros casos, los posibles hiatos se deben a pequeños descuidos en la edición ${ }^{27}$.

23. «No existe ningún caso de hiato, esto es, siempre se produce sinalefa, cuando la palabra final empieza en sílaba átona, incluso cuando dicha palabra comienza con $h$ aspirada, lo cual concuerda con la práctica de Lope.» (Beccaria 1995: 95)

24. Varios de estos versos presentan dos posibles hiatos, uno de los cuales debe pronunciarse como tal para acomodar el verso al recuento silábico. En algunos casos es posible pronunciar con diéresis el grupo -ie- en palabras como bien o cualquiera, licencia ajena a Lope.

25. Este verso, a diferencia de los demás, es un endecasílabo.

26. En su edición, Beccaria enmienda cinco de estos versos. Las enmiendas resultan verosímiles, pues la intervención textual es mínima: 1- para engañar a la Infanta; 2- muy bravo en fuerza y en leyes; 5- que bien declarado estás; 8- y al suegro tuyo vencí; 11- pues que no acertaste agora.

27. No hay hiato entre me y han en el verso 1424, que Beccaria transcribe como «mucho que me han purgado", pero que en realidad debe leer "lo mucho que me han purgado", tal y como figura en el manuscrito (f. 36v): «porque aquesto lo ha causado / lo mucho que me han purgado». Del mismo modo, la supresión, por error, de la palabra que en el verso 2494 crea un hiato ilusorio entre mandaste y ofender: "que en este yermo y soledad habito / desde aquel triste y lamentable día / que mandaste ofender a tus crïados» (vv. 2492-2494). 
Otros rasgos ortológicos contrarios a Lope son un hiato entre vocal final tónica y vocal átona inicial («hará un gran desconcierto», v. 1105) 28, fenómeno que Morley (1927: 540) y Poesse (1949: 73) solo registran en dos ocasiones, y dos casos, también ajenos a Lope, en los que resulta imposible discernir exactamente qué tipo de hiato contienen: $Y$ así yo quiero hacer» (v. 924) y "Oh, hideputa alcahuete» (v. 1504). En el primer caso podría tratarse de un hiato entre dos vocales átonas ( Ylasi) o ante vocal átona con $h$ aspirada (quierol hacer); en el segundo, el hiato puede producirse entre tónica y átona ( $\mathrm{Oh} /$ hideputa) o entre dos átonas (bideputalalcahuete).

En La Otomana se observan asimismo tres hiatos entre vocal final átona e inicial tónica, bastante extraños en Lope (Poesse 1949: 68-72): "Eso no es de creer» (v. 46); «de esto. Tienes razón» (v. 392), y "que será tan fuerte hombre» (v. 2527). En cuanto al primer verso, Poesse (1949: 70) señala que existen cientos de casos de sinalefa ante es, mientras que solo recoge ocho de hiato (cinco de ellos dudosos), a los que hay que añadir uno más anotado por Morley (1927: 540). En el segundo verso, Beccaria suprime el hiato sustituyendo esto por aquesto, enmienda que por lo demás parece innecesaria. Si el verso que se ha conservado se corresponde con el original, constituye una excepción en los usos ortológicos de Lope ${ }^{29}$. En cuanto al 2527, Poesse (1949: 72) solo registra dos casos de hiato antes de hombre, pero ambos son dudosos. Morley, por su parte, no recoge ningún ejemplo.

Otro verso dudoso es el 2160 ("y anda haciendo quimeras»), en el que, o bien se produce hiato entre una vocal final átona y una tónica inicial $(y / a n d a)$, o bien ante vocal átona con $h$ aspirada (andal haciendo). Según Poesse (1949: 68), cuando la primera de las palabras es la conjunción $y$, se produce una sinalefa con la vocal tónica inicial. Además, si las formas anda, andas, andan, etc. aparecen en segundo lugar, el resultado es siempre la sinalefa (Poesse 1949: 69). Así pues, en cualquier caso el verso no se ajusta a la ortología de Lope.

La palabra diablo solo es trisílaba en uno de los 36 casos registrados por Poesse (1949: 41, n. 79), mientras que en todos los demás es bisílaba. En La Otomana tenemos 9 casos de diablo bisílabo ${ }^{30}$, un diablos trisílabo («tus diablos y tu fama», v. 1972) y cinco dudosos, que transcribo a continuación:

$$
\begin{aligned}
& \text { 1- Aquel, hijo, es el diablo (v. 1926) } \\
& \text { 2- del diablo, eterna muerte (v. 1952) } \\
& \text { 3- dese diablo, el cual es (v. 1957) } \\
& \text { 4- diablo. -Sin duda es loco (v. 2159) } \\
& \text { 5- Y los diablos, ¿qué harían? (v. 2199) }
\end{aligned}
$$

28. Con todo, el verso podría contener una omisión por duplografía («hará un grande desconcierto").

29. "There are hundreds of examples of synalepha when esa, -as, -e, -o, -os, or esta, -as, -e, -o, -os is the second word of a group [...]. The examples of hiatus [...] are inconclusive.» (Poesse 1949: 70)

30. Véanse los vv. 109, 1932, 1939, 1941, 1967, 2143, 2148, 2184 y 2187. En este último es posible que en el original figurara cualquier mujer en vez de «cualquiera mujer», de modo que «diablo» sería trisílabo. 
La voz diablo puede ser trisílaba en los cinco casos, pero todos ellos podrían presentar asimismo fenómenos de hiato entre vocales de distintas palabras, de modo que pasaría a ser bisílaba. Así, los versos 1 y 4 podrían contener un hiato ante es, muy extrańo en Lope; los versos 2 y 3 , un hiato entre dos vocales átonas, contrario a los usos ortológicos del Fénix; y el 5, un hiato ante vocal átona con $h$ aspirada, fenómeno que Poesse (1949: 63) recoge solamente en dos ocasiones frente a 2176 de sinalefa. En cualquier caso, estos cinco versos contradicen de nuevo la ortología del Fénix.

En conclusión, a mi juicio la ortología de La Otomana es sin lugar a dudas ajena a la de Lope, al contrario de lo que había afirmado Beccaria. En total los ejemplos superan ampliamente la treintena. Con todo, lo estragado del texto y la probable intervención de manos ajenas al poeta (autores de comedias, actores, copistas, memorillas, etc.) aconsejan ser cautos y no refutar del todo la posible autoría lopesca por motivos exclusivamente ortológicos.

\section{RimA}

Los estudios de J. H. Arjona sobre diferentes aspectos de la rima han permitido establecer criterios objetivos para el análisis de la autenticidad de los textos y las atribuciones dudosas.

Beccaria afirma que en La Otomana "existen unos diez casos de autorrima" (1995: 95). En realidad son más de veinte, pero ninguno de ellos resulta muy relevante por lo que atañe a la autoría. Muchas de las autorrimas se dan entre vocablos con diferentes significados o distintas categorías gramaticales, práctica muy extendida en el Siglo de Oro. En los versos 1098 y 1258 la autorrima afecta a un pronombre (él), pero ambos conllevan un cambio de preposición, caso admitido por la preceptiva (Arjona 1953: 276). Los versos 1932 y 1934 contienen el mismo nombre con idéntico significado, pero en un caso se halla en una afirmación y en otro, en una interrogación ${ }^{31}$. En los versos 2336 y 2340 aparece una autorrima con el verbo ser-uno de los más proclives a padecer este fenómeno- en la que apenas si se percibe un cambio gramatical, pero Arjona (1953: 288-289) rastrea casos semejantes.

Examinemos ahora los cuatro casos que, según Beccaria, no son sino «errores exclusivos de la copia que manejamos y que no existían en la obra original» (1995: 96). El primero forma parte de la siguiente quintilla:

$$
\begin{gathered}
\text { Junto a una cabańa estoy; } \\
\text { quiero ver si alguien responde. }
\end{gathered}
$$

\section{Sale el Niño diablo}

A buscar el diablo voy,

31. "Apparently it was permissible to use any parts of speech as autorhymes provided the type of sentence in which they appeared varied: declarative, interrogative, exclamatory, or imperative.» (Arjona 1953: 297) 
pero, ¿`i acaso se esconde porque buscándole voy?

En su edición, Beccaria sustituye el segundo voy por estoy, lección verosímil. Se sigue produciendo una autorrima -en este caso con estoy-, pero más suave, dada la mayor distancia respecto al primer verso. En cualquier caso, ya hemos comentado que no era extraño rimar una misma palabra en frases afirmativas e interrogativas, por lo que en el texto original, fuera quien fuera su autor, bien podría figurar tanto estoy como voy. Otro tanto ocurre entre los versos 299 («¿podríalo yo saber?») y 301 («Cualquier cosa has de saber»), en los que el verbo saber aparece en posición de rima y con el mismo significado. En este caso, además, el verbo que acompaña a los infinitivos es distinto; parece ser que muchos dramaturgos, entre ellos Lope, practicaron este tipo de autorrima (Arjona 1953: 284). Transcribo a continuación el siguiente caso citado por Beccaria:

\author{
Hijo por mi bien nacido, \\ ven abrazar a tu padre \\ agora que eres nacido. \\ ¡Desdichada de tu madre \\ y de quien la ha conocido!
}

(vv. 2505-2509)

En su artículo, Arjona (1953: 291) cita varias razones por las que dos adjetivos idénticos podían aparecer en posición de autorrima. Una de ellas era la presencia del verbo ser, que exige que uno de los adjetivos funcione como atributo (como ocurre con el segundo nacido). Otra, que uno de los dos adjetivos formara parte de un vocativo, tal como sucede en el primer verso.

Por último, la siguiente autorrima afecta a palabras con significado y forma gramatical idénticos, caso no aceptado por la preceptiva y considerado un error en la época:

Vamos al bien deseado,
porque de mis gentes todas
sea luego celebrado
el principio deseado
de tu partida y mis bodas. $\quad$ (vv. 1866-1870)

Es probable que varias de las autorrimas aquí estudiadas sean consecuencia de un error de copia o del capricho o despiste de actores y autores de comedias $^{32}$. Los dramaturgos del Siglo de Oro incurrieron, no obstante, en las más variopintas autorrimas, ingeniosas y acrobáticas unas, sosas y ramplonas otras. El propio Arjona (1953: 300) documenta casos semejantes al último analizado, incluso en autógrafos de Lope.

32. Un caso muy claro, que cabe añadir a los señalados por la editora, es el que afecta a los siguientes versos: «Si llamas, por tu agudeza, / diablo a cualquiera mujer, / habrélo de conceder; / pero por naturaleza / ninguna lo puede ser, / que todas somos humanas / en cuerpos, talles y nombres. / Y si algunas son tiranas, / es porque son, de los hombres / en naturaleza, humanas» (vv. 2186-2195). Esta última palabra debe sustituirse por hermanas ("las mujeres son, en naturaleza, hermanas de los hombres"). Por otro lado, en el pasaje transcrito Beccaria lee cuerpos tales en vez de cuerpos, talles, error que no aparece en el manuscrito, que lee talles (f. 54r). 
Por mi parte, he advertido la presencia en La Otomana de varias rimas defectuosas. En primer lugar, una redondilla combina rima asonante con rima consonante, práctica condenada por los preceptistas:

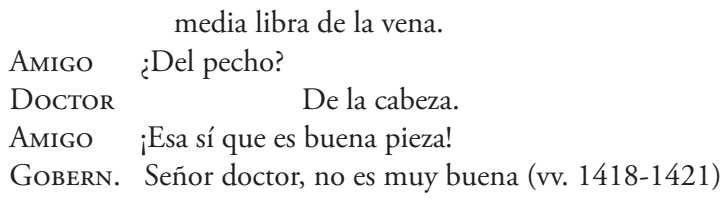

La rima asonante en $e$ - $a$ que se produce entre los versos 1 y 4 de la redondilla y los versos 2 y 3 se consideraba defectuosa. Arjona (1955: 126) halló dieciséis casos de mezcla de rima asonante y consonante en cuarenta autógrafos de Lope: se trata de un error que el Fénix comete raramente, y desde luego en menor medida que la mayoría de sus contemporáneos.

La comedia contiene además dos casos de rima asonante en versos que deberían rimar en consonante:

$$
\begin{aligned}
& \quad \text { sin mí os habéis de quedar, } \\
& \text { pues van reyes a guardar } \\
& \text { los ganados estranjeros, } \\
& \text { y quedan los ganaderos } \\
& \text { en vuestra silla real. }
\end{aligned}
$$

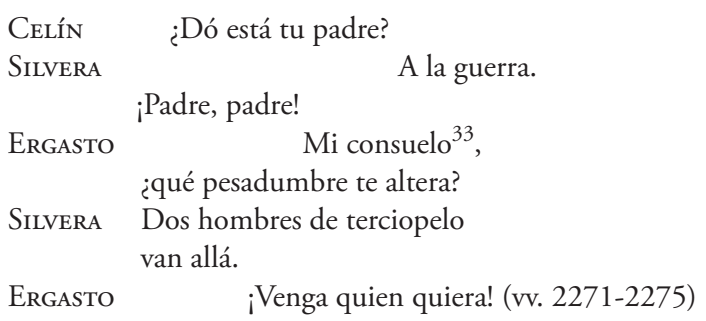

Ninguno de los dos pasajes contiene errores de copia evidentes, de modo que es posible que se trate de defectos achacables al poeta. Arjona (1955: 126127) encontró once casos de falsa rima consonante en los cuarenta autógrafos lopescos objeto de su estudio.

Por último, la obra contiene algunos casos de ausencia de rima que vale la pena analizar. Beccaria lleva a cabo varias enmiendas acertadas que la restauran y que dan cuenta del maltrecho estado del texto. Sin embargo, otros ejemplos no han sido advertidos por la editora. Uno de ellos es la quintilla comentada en el apartado dedicado a la versificación estrófica, en la que era necesario enmendar «modo» por «suerte», recuperando así la rima sin variar en lo más mínimo el sentido del pasaje. Más compleja es la siguiente:

33. El manuscrito lee "consuelo mio» (f. 56v). La enmienda de Beccaria, mi consuelo, resulta muy conveniente, puesto que restaura la rima sin modificar un ápice el sentido del texto. 


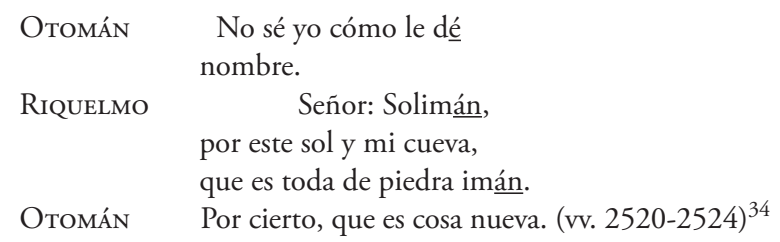

Como en otros casos, en el manuscrito (f. 62r) este pasaje contiene versos mal partidos, ya que «nombre» aparece al final del primero. Beccaria subsana con acierto este error, pero en cambio no parece advertir la falta de rima que contiene la lectura resultante. Sin embargo, es necesario realizar una enmienda: Otomán no se plantea en verdad qué nombre debería dar al niño («No sé yo cómo le dé / nombre»), sino cómo le llaman («No sé yo cómo le dan / nombre»). El contexto resulta esencial para entender por qué hay que sustituir dé por dan (escrito probablemente $d \bar{a}$, hecho que favorecería el error de copia): el rey Otomán acaba de descubrir que un niño, abandonado por su madre nada más nacer, es hijo suyo. Otomán pregunta por su nombre, y solo Riquelmo puede darle la respuesta, pues fue él quien encontró al recién nacido, al que crió y educó en el monte y en la "cueva obscura» (v. 1259) en la que han vivido. Así pues, no le «dan allí mismo el nombre de Solimán» (Beccaria 1996: 224), sino que Otomán acepta el que le había puesto Riquelmo: «Yo le confirmo ese nombre» (v. 2525). El defecto de la rima, pues, es subsanable ${ }^{35}$. Otro tanto sucede en la siguiente quintilla:

\begin{tabular}{ll}
$\begin{array}{l}\text { Tolomeo } \\
\text { Lucinda }\end{array}$ & \multicolumn{1}{c}{ ¡Válgame Dios! } \\
Tolomeo & $\begin{array}{l}\text { así los ojos te encubres? } \\
\text { Sabrás que no los tapé, } \\
\text { señora, por no mirarte, } \\
\text { sino porque te miré. }\end{array}$
\end{tabular}

(vv. 1687-1691)

Es muy probable que en el proceso de transmisión del texto se llevara a cabo la sustitución del verbo «taparte» (que rima con «mirarte» y se repite en el verso siguiente, los tapé) por «te encubres», error que no implica cambio semántico alguno.

Por último, la siguiente redondilla contiene una falsa rima dudosa:

\begin{tabular}{ll} 
Celín & \multicolumn{1}{c}{ iAlá os guarde! } \\
ERgasto & \multicolumn{1}{c}{$\begin{array}{c}\text { Él os guíe. } \\
\text { Quiero hacer que luego, al punto, } \\
\text { por vitüalla se envíe. } \\
\text { Infl fin, Fortuna. Que un tonto } \\
\text { se ensoberbece y se engríe. }\end{array}$}
\end{tabular}

(vv. 2301-2305)

\footnotetext{
34. Tal y como advirtió Iriso (1997: 224), la edición de Beccaria atribuye esta última intervención a Riquelmo, error que no procede del manuscrito (f. 62r).

35. Por lo demás, la rima entre dan y Otomán ha aparecido poco antes (vv. 2431-2432).
} 
En su edición, Beccaria sustituye «al punto» por «al pronto». Sin embargo, una búsqueda de dicha expresión en el Teso no arroja ningún resultado ${ }^{36}$. Quizás bastaría con la palabra "pronto", aunque su uso adverbial es muy moderno, ya que en la época se usaba fundamentalmente como adjetivo, según se recoge en el Diccionario de Autoridades ${ }^{37}$.

En síntesis, el empleo de las rimas en La Otomana se ajusta en general a los cánones de la época y a los de Lope en particular.

\section{Conclusiones}

El mal estado de La Otomana aconseja ser prudentes a la hora de extraer conclusiones del estudio de la ortología y la rima, rasgos que pueden verse seriamente afectados por la labilidad inherente al texto teatral del Siglo de Oro. En cambio, el análisis de la versificación estrófica resulta mucho más fidedigno, puesto que se trata de un aspecto que acusa en un grado mucho menor el desgaste textual propio del proceso de transmisión.

En una reseña a la edición de Beccaria, Nancy Mayberry se mostraba partidaria de llevar a cabo un análisis profundo de la métrica, la ortología y la rima de La Otomana antes de atribuirla a Lope: «until further studies demonstrate that the play does indeed follow Lope's metrical, rhyming, and spelling practices, I would remain hesitant to accept wholeheartedly the claim of Lope's authorship.» (Mayberry 1997: 384) ${ }^{38}$ La versificación estrófica y la ortología no se corresponden con los usos de Lope, y únicamente el análisis de la rima parece ser acorde con su escritura. Así pues, por los habituales medios objetivos de atribución de comedias no puede asegurarse que La Otomana sea obra de Lope de Vega. Si lo es o no, en el estado textual que nos ha llegado es irreconocible como tal. En cambio, su versificación se ajusta a la de varios dramaturgos que escribieron en torno a 1600, singularmente a la del grupo de los valencianos.

Centrándonos en el terreno de la versificación, si se quisiera defender a capa y espada la autoría lopesca, habría que suponer que La Otomana es fruto de la voluntad de experimentación métrica por parte de Lope, que, de modo absolutamente excepcional -cuando menos en relación a su producción conservada-, habría querido componer una comedia con un porcentaje de quintillas tan elevado como el de las firmadas por algunos de sus contemporáneos. Esta es una hipótesis imposible de demostrar y no poco arriesgada. Mucho más verosímil resulta, a mi juicio, plantear la posibilidad de una profunda intervención por parte de un autor de comedias -o de un poeta a su servicio- o recuperar la idea, lanzada por Lapesa, de la mediación de un memorilla, que habrían alterado profundamente la versificación estrófica,

36. En el Corde se encuentra un solo ejemplo, perteneciente al Arauco domado, de Pedro de Ойa (1596).

37. Véanse, además, los ejemplos que se obtienen de una búsqueda en Teso.

38. De la misma opinión se mostraba Carrasco Urgoiti (2001: 20). 
potenciando el uso de las quintillas por encima del resto de metros; en este sentido, podría llegar a hablarse de una refundición de la supuesta obra original de Lope. Debería de tratarse, eso sí, de una refundición temprana ${ }^{39}$, llevada a cabo en los años en los que aún era posible encontrar obras escritas con unos porcentajes de quintillas tan amplios, es decir, en torno a 1600 (muy poco después, por tanto, de 1598-1599, fecha en la que supuestamente Lope habría escrito la comedia, a juzgar por el personaje de Lucinda). Esto explicaría por un lado los usos métricos y ortológicos contrarios a Lope-sin olvidar además que la transmisión posterior de la comedia habría deturpado aún más el texto-, a la vez que justificaría la semejanza onomástica con $E l$ Otomano famoso, citado en el Peregrino, así como la presencia de las rimas asociadas al nombre de Lucinda típicamente lopescas. Esta hipótesis tiene la ventaja de que permite conjugar las pruebas a favor y en contra de la autoría de Lope. Con todo, ¿podría seguir considerándose "de Lope" un texto que hubiera sufrido tantas modificaciones? Sea como fuere, al contrario de lo que afirma Beccaria -gracias a cuya labor y edición hemos tenido noticia de tan apasionante obra-, los datos de que hoy disponemos no son, a mi entender, suficientes como para atribuir La Otomana a Lope de Vega, por lo que, hasta que investigaciones futuras puedan arrojar nueva luz sobre el asunto, parece más prudente seguir considerándola una de tantas comedias áureas de dudosa autoría ${ }^{40}$.

39. Un fenómeno de reescritura semejante, por tanto, al que analizó e ilustró con su pericia habitual Gonzalo Pontón (2001).

40. Así pues, se trata de un caso parecido al que acaba de estudiar, de modo ejemplar, Fernando Rodríguez-Gallego (2016). 


\section{Bibliografía}

Ambrosi Paola (ed.), Vega, Lope de, La pastoral de Jacinto, Kassel, Reichenberger, 1997. Arata Stefano, Miguel Sánchez il "Divino" e la nascita della "Comedia Nueva”, Salamanca, Universidad de Salamanca, 1989, 97 pp.

Arjona J. H., "The Use of Autorhymes in the XVIIth Century Comedia», Hispanic Review, 1953, 21, 4, pp. 273-301.

- «Defective Rhymes and Rhyming Techniques in Lope de Vega's Autograph Comedias", Hispanic Review, 1955, 23, 2, pp. 108-128.

Beccaria Lola (ed.), Vega, Lope de, El Otomano famoso, Barcelona, Ediciones Áltera, 1996, 231 pp.

Boadas Sònia (ed.), Vega, Lope de, La ingratitud vengada, en López Martínez, J. E. (coord.), Comedias de Lope de Vega. Parte XIV. Tomo II, Madrid, Gredos, 2015, pp. 911-1052.

Bruerton Courtney, «Is Aguilar the Author of Los amigos enojados?», Hispanic Review, 1944, 12, 3, pp. 223-234.

— «La versificación dramática española en el período 1587-1610», Nueva Revista de Filología Hispánica, 1956, 10, pp. 337-364.

Carrasco Urgoiti María Soledad, "La comedia del siglo XVII y la frontera norteafricana», en Strosetzki, C. (ed.), Actas del V Congreso de la Asociación Internacional Siglo de Oro (AISO). Münster 20-24 julio 1999, Madrid-Frankfurt am Main, Iberoamericana-Vervuert, 2001, pp. 13-31.

Cigüeña Beccaria María Dolores, "Una comedia perdida de Lope de Vega», Reales sitios, 1994, 121, pp. 46-50.

Cigüeña Beccaria Lola, "Hallazgo de una comedia perdida de Lope de Vega: El Otomano famoso», Edad de Oro, 1995, XIV, pp. 85-107.

Corde $=$ Real Academia Española, Corpus diacrónico del español. Banco de datos CORDE [En línea]. Real Academia Española [Página consultada el 3 de noviembre de 2014]. Disponible en http://www.rae.es

Cornejo Manuel (ed.), Vega, Lope de, El Arenal de Sevilla, en Fernández, L. y Pontón, G. (coords.), Comedias de Lope de Vega. Parte XI. Tomo II, Madrid, Gredos, 2012, pp. 459-610.

Dixon Victor, «La intervención de Lope en la publicación de sus comedias», Anuario Lope de Vega, 1996, II, pp. 45-63.

Fernández Rodríguez Daniel, «Nuevos datos acerca de los repertorios teatrales en el primer catálogo de El peregrino en su patria», Studia Aurea, 2014, 8, pp. 277-314.

Iriso Ariz Silvia, «Lope de Vega, El Otomano famoso, edición de Lola Beccaria, Ediciones Áltera, Barcelona, 1996, 231 pp.» [reseña], Anuario Lope de Vega, 1997, III, pp. 221-224.

Lapesa Rafael, «Prólogo», en Vega, Lope de, El Otomano famoso, ed. L. Beccaria, Barcelona, Ediciones Áltera, 1996, pp. 7-8.

Le Gentil Pierre, La poésie lyrique espagnole et portugaise à la fin du Moyen Âge, Ginebra, Glatkine, 1981, 2 vols.

Mayberry Nancy, «Vega, Lope de. El Otomano famoso (o la famosa comedia otomana). 
Edición de Lola Beccaria. Barcelona: Ediciones Áltera, 1996. Paper. 232 pp. 1,900 pesetas.» [reseña], Bulletin of the Comediantes, 1997, 49, 2, pp. 383-384.

Morley, S. Griswold, "Ortología de cinco comedias autógrafas de Lope de Vega», en Estudios eruditos in memoriam de Adolfo Bonilla y San Martín, Madrid, Ratés, I, 1927, pp. 525-544.

Morley S. Griswold, «Objective Criteria for Judging Authorship and Chronology in the Comedia», Hispanic Review, 1937, 5, 4, pp. 281-285.

Morley, S. Griswold y Bruerton, Courtney, Cronología de las comedias de Lope de Vega, Madrid, Gredos, 1968, 693 pp.

Ojeda Calvo, María del Valle (ed.), El hijo de la cuna de Sevilla, Kassel, Reichenberger, 1996, 338 pp.

Poesse Walter, The Internal Line-Structure of Thirty Autograph Plays of Lope de Vega, Bloomington, Indiana University, 1949, $105 \mathrm{pp}$.

Pontón Gonzalo, "Una refundición temprana de Las mudanzas de fortuna», Anuario Lope de Vega, 2001, 7, pp. 247-351.

Ramos Rafael (ed.), Vega, Lope de, La prisión sin culpa, en Ramos, R. (coord.), Comedias de Lope de Vega. Parte VIII, Lérida, Milenio-Universitat Autònoma de Barcelona, 2009, II, pp. 871-984.

Rodríguez-Gallego Fernando, "Otra comedia del Siglo de Oro en busca de autor: Satisfacer callando o Los hermanos encontrados", Studia Aurea, 2016, 10, pp. 393410.

Teso= Teatro Español del Siglo de Oro, versión 3.00. [Recurso electrónico]. ChadwyckHealey, 1997-1998. 1 CDROM.

Williamsen Vern G., "The versification of Antonio Mira de Amescua's comedias and of some comedias attributed to him», en Williamsen, V. G. y Michael Atlee, A. F. (eds.), Studies in honor of Ruth Lee Kennedy, Chapel Hill, Estudios de Hispanófila, 1977, pp. 151-167. 